\title{
A double-label study of efferent projections from the Edinger-Westphal nucleus in goldfish and kelp bass
}

\author{
John C. Wathey and Mario F. Wullimann* \\ Neurobiology Unit, Scripps Institution of Oceanography, Department of Neurosciences, A-001, University \\ of California, San Diego, La Jolla, CA 92093 (U.S.A.)
}

(Received 25 May 1988; Revised version received 20 June 1988; Accepted 5 July 1988)

Key words: Cerebellum; Ciliary ganglion; Edinger-Westphal nucleus; Fluoro-Gold; Goldfish; Horseradish peroxidase; Kelp bass; Teleost

The Edinger-Westphal nucleus in goldfish was identified by retrograde labeling from the ciliary ganglion. In the same animals a few neurons near this nucleus (perinuclear Edinger-Westphal neurons) were labeled by a different retrograde tracer injected into the cerebellum. No double-labeled cells were found. Similar results were obtained in kelp bass, except that in this species no cerebellar-projecting perinuclear neurons were observed. Cerebellar-projecting Edinger-Westphal neurons have previously been described in some mammals, but not in other vertebrates. Therefore the homology of cerebellar-projecting cells of the Edinger-Westphal region in mammals and teleost fishes is doubtful.

The Edinger-Westphal nucleus (EW) of primates is a midbrain cell group that controls ocular accommodation and the pupillary reflex via a synapse in the ciliary ganglion $[1,2,5,16]$. Although putative homologues of $\mathrm{EW}$ have been proposed for many other vertebrate groups, the midbrain neurons presynaptic to the ciliary ganglion have been identified by modern experimental techniques in only a few non-primate species (for review see ref. 21). In some of these species the connections of EW were shown to be more complex than previously assumed. For example, in cats $[11,20]$ and rabbits [7], most of the preganglionic neurons lie outside of EW (as classically defined by descriptive anatomy). Furthermore, recent experiments have shown that many EW cells project to the spinal cord, cerebellum and other lower brainstem structures in several primates [2-4, 16], and non-primate mammals [8-12]. The functions of these efferent pathways, and their relationship (if any) to the preganglionic pathway, are not fully understood.

A homologue of $\mathrm{EW}$ was recently identified for the first time in teleost fishes (kelp

*Present address: Georg-August-Universität Göttingen, Zentrum Anatomie, Kreuzbergring 36, D-3400 Göttingen, F.R.G.

Correspondence: J.C. Wathey. Present address: Division of Biology 216-76, California Institute of Technology, Pasadena, CA 91125 , U.S.A. 

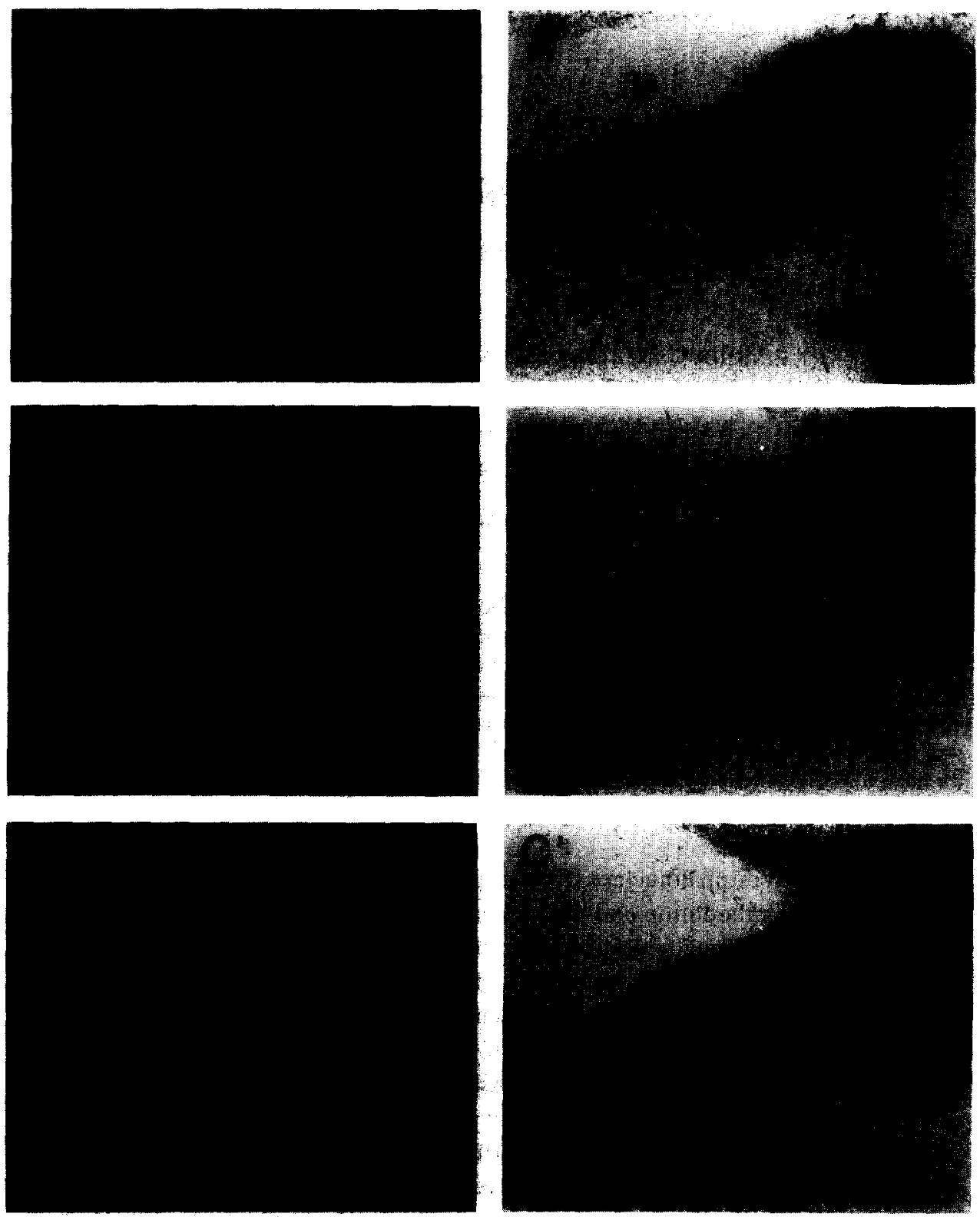

Fig. 1. Three transverse sections in rostrocaudal sequence through the midbrain of a goldfish, showing the Edinger-Westphal nucleus (EW) and one of its cerebellar-projecting perinuclear neurons. Horseradish peroxidase (HRP) was injected into the cerebellum and Fluoro-Gold was applied to the oculomotor nerve proximal to the ciliary ganglion. Each section is shown both in ultraviolet illumination (left micrograph of each pair) to reveal the Fluoro-Gold tracer, and in visible light to reveal HRP reaction product. A-A': this section contains a perinuclear neuron of EW, retrogradely labeled with HRP from the cerebellum ( $\mathrm{A}^{\prime}$, arrow), but not labeled with Fluoro-Gold (A). HRP-positive cells of the dorsal tegmental nucleus (DT) are also visible $\left(A^{\prime}\right)$. $B-B^{\prime}$ and $C-C^{\prime}$ : two adjacent sections taken $360 \mu$ m caudal to that in $A-A^{\prime}$, 
bass and sand bass) by retrograde labeling from the ciliary ganglion [21], but the possible existence of efferents from this nucleus to the cerebellum was not investigated. The present study was undertaken to address this question. It was prompted in part by the recent discovery of a small group of cerebellar-projecting neurons near the oculomotor nucleus in the goldfish and in the green sunfish [22]. These cells are similar in location and appearance to the preganglionic EW neurons of the kelp bass and sand bass [21]. We used a double-labeling technique to determine whether or not single EW neurons innervate both the ciliary ganglion and the cerebellum in goldfish and kelp bass.

Six kelp bass, Paralabrax clathratus (150-300 g, b.wt.) and 5 goldfish, Carassius auratus $(7-9 \mathrm{~g})$, were used. The animals were anesthetized $(0.01 \%$ tricaine methane sulfonate) for surgery. In each case the oculomotor nerve and ciliary ganglion were exposed on one side by enucleation of the eye, using the method of Springer and Prokosch [18]. In one kelp bass case, horseradish peroxidase (HRP) conjugated with wheat germ agglutinin (Sigma L2384) was applied to the ganglion as described elsewhere [21], and about $1 \mu \mathrm{l}$ of 10\% Fluoro-Gold [15] was injected into the ipsilateral cerebellar corpus. In the remaining 5 kelp bass and in all goldfish cases, HRP (Sigma VI) was injected unilaterally into the cerebellar corpus by pin injections (for details see ref. 22). In these kelp bass cases about $20 \mathrm{nl}$ of 10\% Fluoro-Gold was injected into the ipsilateral ciliary ganglion via a glass micropipette. In the goldfish the ciliary ganglion was small and fused with the oculomotor nerve; discrete injections into the ganglion could not be made in these animals. Instead the ipsilateral oculomotor nerve was cut at or proximal to the ganglion, and crystals of Fluoro-Gold were applied to the proximal stump.

Survival times ranged from 4 to 16 days for the kelp bass and from 10 to 11 days for the goldfish. The animals were deeply anesthetized and perfused transcardially with teleost Ringer's solution, followed by $4 \%$ buffered paraformaldehyde fixative (see ref. 21 for further details of histological processing). Brains were sectioned on a cryostat at $40 \mu \mathrm{m}$ (kelp bass) or $30 \mu \mathrm{m}$ section thickness (goldfish). Tetramethyl benzidine was used as the HRP chromagen [13].

In the 5 goldfish cases, somatic oculomotor neurons were heavily labeled with Fluoro-Gold from the cut oculomotor nerve. In agreement with the findings of Scherer [14], labeled cells were seen throughout the oculomotor nucleus on the ipsilateral side, but only in the ventromedial subdivision on the contralateral side (Fig. $1 \mathrm{~B}, \mathrm{C})$.

In addition to these cells, there was also a distinct group of smaller Fluoro-Gold-

showing neurons retrogradely labeled with Fluoro-Gold. The Edinger-Westphal nucleus (EW) comprises a distinct group of neurons lateral to and smaller than the neurons of the somatic oculomotor nucleus (NOc); arrows in B indicate the border between the two nuclei. In the most caudal section a few EW neurons can be seen in a more lateral position ( $C$, arrowheads). Note the absence of HRP in the EW neurons $\left(B^{\prime}, C^{\prime}\right)$. All micrographs are shown at identical magnification and orientation; scale bar is $100 \mu \mathrm{m}$, dorsal is up and the midline is near and parallel to the left edge. TMC, anterior mesencephalo-cerebellar tract; $\mathrm{V}$, mesencephalic ventricle. 
positive neurons lateral to the somatic oculomotor cells in each of the 5 cases (Fig. $1 \mathrm{~B}, \mathrm{C})$. We identify these cells as preganglionic EW neurons on the basis of the following criteria, all of which are characteristic of EW neurons in Paralabrax [21]: (1) they lie dorsal and lateral to the somatic oculomotor nucleus at its rostral end; (2) they are smaller and more polygonal in shape than somatic oculomotor cells; (3) they are labeled only on the ipsilateral side; and (4) they extend laterally beyond the medial longitudinal fasciculus (in a previous study [14], retrograde transport from the extraocular muscles of goldfish labeled no neurons this far lateral to the medial longitudinal fasciculus). In our goldfish cases, EW neurons could typically be seen in only two consecutive sections, indicating a rostro-caudal extent of about $60 \mu \mathrm{m}$ for the entire nucleus.

In the same 5 goldfish cases, retrograde transport of HRP from the cerebellar corpus labeled diencephalic, mesencephalic and rhombencephalic nuclei as described by Wullimann and Northcutt [22]. At the level of the oculomotor nucleus, the most prominent HRP-positive neurons were the small, nearly spherical cells of the dorsal tegmental (DT) nucleus (Fig. 1 A', B', C'). In 3 cases, however, there were some additional HRP-positive neurons scattered between DT and EW. These could be distinguished from DT cells not only by their position but also by their larger size and different shape (Fig. 1 $\mathrm{A}^{\prime}$; see also ref. 22, in which the morphology of these cells is revealed in greater detail by the Hanker-Yates method). Because of their proximity to EW, we refer to these cells as perinuclear neurons of EW. Such cells could be found over a rostro-caudal extent of about $600 \mu \mathrm{m}$, extending to the rostral tip of the DT. Neither these cells nor the preganglionic EW neurons were double-labeled.

In all 6 kelp bass cases EW was retrogradely labeled from the ciliary ganglion, in agreement with a previous study [21]. As expected from previous results in two other teleosts [22], retrograde transport from the cerebellum was observed in DT. There were, however, no double-labeled cells in EW, nor were there any neurons near EW (other than DT neurons) that had been retrogradely labeled from the cerebellum.

The absence of cerebellar-projecting perinuclear cells in the kelp bass cases may represent a real species difference. Alternatively, it is possible that our injections into the cerebellar corpus of kelp bass did not include the terminal fields of the perinuclear cells. Differences in cerebellar morphology could account for the latter alternative. The corpus bends rostrally in kelp bass but caudally in goldfish. Since the injections were made from the dorsal aspect, the bulk of the tracer went into topologically different regions in the two species. Inputs to the corpus are compartmentalized in goldfish and in the green sunfish (Wullimann and Northcutt, unpublished observations). Furthermore, injections into the corpus of the kelp bass were relatively smaller than those made in goldfish, because the kelp bass brains were larger in absolute size.

The preganglionic EW cells in goldfish presumably subserve ocular accommodation [17], as has been demonstrated in two other teleost species [21]. We made no attempt to count these cells, but the axon counts of Scherer [14] indicate that there are, on average, about 56 axons innervating the ciliary ganglion of the goldfish.

Cerebellar-projecting neurons in the EW complex have been found in cats $[11,19]$ and in the monkey Macaca fuscata [16]. Double-labeling experiments [11] show that 
these cells in cats are distinct from the preganglionic neurons. These findings appear similar to our results in goldfish. However, cerebellar-projecting neurons in or near EW have not been described in other groups of vertebrates. Without such evidence it is impossible to establish the homology of these systems in teleosts and mammals. Given the small number of cells involved, it is possible that such projections were overlooked in studies of cerebellar afferents in other species.

The function of cerebellar-projecting EW cells is unknown. In cats, at least some of these neurons send collaterals to the spinal cord and may contain substance $P$ [11] and cholecystokinin [12]. Cells immunoreactive for these peptides have also been found in EW of rats and are believed to be part of a nociceptive pathway [6]. It has also been suggested that cerebellar-projecting EW neurons in cats convey visual information [19]. Further comparative studies could test these hypotheses and perhaps elucidate the evolution of the pathways involved.

We thank Drs. R.G. Northcutt and T.H. Bullock for their critical review of the manuscript, and Dr. E. Fiebig for help with some of the histology. This work was funded by NIH and NSF grants to Drs. Northcutt and Bullock. M.F.W. was supported by the Swiss National Science Foundation.

1 Akert, K., Glicksman, M.A., Lang, W., Grob, P. and Huber, A., The Edinger-Westphal nucleus in the monkey. A retrograde tracer study, Brain Res., 184 (1980) 491-498.

2 Burde, R.M. and Loewy, A.D., Central origins of oculomotor parasympathetic neurons in the monkey, Brain Res., 198 (1980) 434439.

3 Carlton, S.M., Chung, J.M., Leonard, R.B. and Willis, W.D., Funicular trajectories of brainstem neurons projecting to the lumbar spinal cord in the monkey (Macaca fascicularis): a retrograde labeling study, J. Comp. Neurol., 241 (1985) 382-404.

4 Castiglioni, A.J., Gallaway, M.C. and Coulter, J.D., Spinal projections from the midbrain in monkey, J. Comp. Neurol., 178 (1978) 329-346.

5 Clarke, R.J., Coimbra, C.J.P. and Alessio, M.L., Distribution of parasympathetic motoneurons in the oculomotor complex innervating the ciliary ganglion in the marmoset Callithrix jacchus, Acta Anat., 121 (1985) 53-58.

6 Innis, R.B. and Aghajanian, G.K., Cholecystokinin-containing and nociceptive neurons in rat Edinger-Westphal nucleus, Brain Res., 363 (1986) 230-238.

7 Johnson, D.A. and Purves, D., Post-natal reduction of neural unit size in the rabbit ciliary ganglion, J. Physiol. (Lond.), 318 (1981) 143-159.

8 Kuypers, H.G.J.M. and Maisky, V.A., Funicular trajectories of descending brain stem pathways in cat, Brain Res., 136 (1977) 159-165

9 Leong, S.K., Shieh, J.Y. and Wong, W.C., Localizing spinal-cord-projecting neurons in adult albino rats, J. Comp. Neurol., 228 (1984) 1-17.

10 Loewy, A.D. and Saper, C.B., Edinger-Westphal nucleus: projections to the brain stem and spinal cord in the cat, Brain Res., 150 (1978) 1-27.

11 Maciewicz, R., Phipps, B.S., Foote, W.E., Aronin, N. and Difiglia, M., Distribution of substance Pcontaining neurons in the cat Edinger-Westphal nucleus: relationship to efferent projection systems, Brain Res., 270 (1983) 217-230.

12 Maciewicz, R., Phipps, B.S., Grenier, J. and Poletti, C.E., Edinger-Westphal nucleus cholecystokinin immunocytochemistry and projections to spinal cord and trigeminal nucleus in the cat, Brain Res., 299 (1984) 139-145.

13 Mesulam, M.-M., Tetramethyl benzidine for horseradish peroxidase neurohistochemistry: a non-carcinogenic blue reaction-product with superior sensitivity for visualizing neural afferents and efferents, 
J. Histochem. Cytochem., 26 (1978) 106-117.

14 Scherer, S.S., Reinnervation of the extraocular muscles in goldfish is nonselective, J. Neurosci., 6 (1986) 764773 .

15 Schmued, L.C. and Fallon, J.H., Fluoro-Gold A new fluorescent retrograde axonal tracer with numerous unique properties, Brain Res., 377 (1986) 147 154.

16 Sekiya. H., Kawamura, K. and Ishikawa, I, Projections from the Edinger-Westphal complex of monkeys as studied by retrograde axonal transport of horseradish peroxidase, Arch. Ital. Biol., 122 (1984) $311-320$.

17 Sivak, J.G., Interrelation of feeding behavior and accommodative lens movements in some species of North American freshwater fishes, J. Fish. Res. Board Can., 30 (1973) $1141-1146$.

18 Springer, A.D. and Prokosch, J.H., Surgical and intensification procedures for defining visual pathways with cobaltous-lysine, J. Histochem. Cytochem., 30 (1982) 1235-1242.

19 Sugimoto, T., Itoh, K. and Mizuno, N., Direct projections from the Edinger-Westphal nucleus to the cerebellum and spinal cord in the cat: an HRP study, Neurosci. Lett., 9 (1978) 17-22.

20 Toyoshima, K., Kawana, E. and Sakai, H., On the neuronal origin of the afferents to the ciliary ganglion in cat, Brain Res., 185 (1980) 67-76.

21 Wathey, J.C. Identification of the teleost Edinger-Westphal nucleus by horseradish peroxidase labeling and by electrophysiological criteria, J. Comp. Physiol. A, 162 (1988) 511-514

22 Wullimann, M.F. and Northcutt, R.G., Connections of the corpus cerebelli in the green sunfish and the common goldfish: a comparison of perciform and cypriniform teleosts, Brain Behav. Evol., in nress. 